up to the 60 per cent. of the prime fat steer, but at an average of 56 per cent. was still high enough to secure a place in the first grade of quality. What these figures mean in terms of beef output is demonstrated by Prof. Wood by a comparison with the results of pre-war experiments, from which it would appear that the decrease in oilcake consumption from $8 \mathrm{lb}$. to $I_{2} \frac{1}{2} \mathrm{~b}$. per head per day only reduces the liveweight increase by $3: 3$ per cent., and the meat output by 9 per cent. The results show further that from the point of view of profit the high cake ration would assuredly be a mistake at the present time, since for each extra pound of beef produced I $3 \mathrm{lb}$. of cake costing about $2 s$, would be consumed.

Even more far-reaching conclusions as to the desirability of aiming at a lower stage of fatness in beef production under present conditions are arrived at by Mr. K. J. J. Mackenzie and Dr. F. H. A. Marshall from investigations of which a summary is given in the September issue of the same journal. These conclusions are based upon data obtained with ninety-two beasts of different degrees of "ripeness" specially selected for the purpose, weighed and slaughtered under conditions permitting of exact observation. The observations were extended further to the edibility of selected portions of the carcass and the proportion of waste involved in their consumption. From the data obtained the conclusions are drawn that the ordinary method of judging the condition of a beast by "handling" may often lead to serious errors of judgment as to its fitness for the butcher, generally resulting in far too many beasts being kept beyond the most economic time for killing; that beyond a certain point further increase in weight does not contribute effectively to the meat supply, being mainly waste fat; and that no serious complaint on the ground of quality can be brought against the meat from the half-fat beast, the consumption of which is attended with the minimal quantity of waste.

On certain points of detail the practical man will doubtless find these observations not entirely convincing, but the general support they afford to the policy of retrenchment in cattle-feeding can scarcely be questioned.

C. C.

\section{STATE ASSISTANCE TO THE DYE INDUSTRY.}

A MEMORANDUM (Cd. 9194, price $2 d$.) has just been issued by the Board of Trade giving details of the scheme for the allocation and administration of the funds provided by Parliament for assistance in the development of the dye industry. It is pointed out that the primary object of the financial assistance to be given is to make the British textile users of dyes independent of German dyestuffs, and to enable the manufacturers to bring down the cost of production to a point at which competition with the large-scale industry of Germany will be commercially possible. Loans and grants of money are to be given to assist in the provision of buildings and plant, and for the maintenance of a system of research. These funds are additional to and independent of the moneys already advanced to the firm known as British Dyes, Ltd. There are dyes which at the present time are not being manufactured in this country at all, or are being made in quantities insufficient for the reasonable needs of dye users, and in this direction especially encouragement is needed.

As to the work of research distinct from the technical routine of manufacturing operations, it is now recognised as an inherent part of the industry, and that it properly enters into the cost of production, since experience shows that in ncrmal times a constant flow of new colours or varieties of colours is necessary for the maintenance of those dye-using trades which are subject to outside competition. It is also acknowledged that, while continued research must be carried on, it does not follow that commercial advantages may be immediately secured. The administration of the scheme will be carried out by (I) a loan and grant committee, (2) a trade and licensing committee, (3) an inspector of research, and (4) an inspector of accounts.

The business of the trade and licensing committee will be to determine what colours and intermediate products shall be licensed to be imported into the country after the war, and in what quantities, and to advise the Commissioner as to the colours and intermediates the manufacture of which should be specially encouraged, and the order of their importance. The committee will consist of four representatives of colour users and four representatives of dye manufacturers under an independent chairman appointed by the Board of Trade.

The inspector of research will occupy an important and somewhat difficult position. It is obvious that he must be a highly qualified "organic" chemist with special knowledge of the production of intermediates, as well as dyes. By his reports to the Dye Commissioner he will practically control the work that goes on in all the research laboratories connected with the works, and as the connection between the experiments actually in progress and the ultimate bearing of the results on industrial operations is often not very obvious, a good deal of patience and discretion will need to be exercised.

Conditions relative to the rate of interest to be charged on loans and the amount to be set aside for depreciation and obsolescence of plant and buildings, as well as for the repayment of the loans, are set forth in the memorandum.

\section{COMMERCIAL AVIATION.}

THE subject of commercial aviation is one that has attracted a great deal of attention during the latter phases of the war, and now that hostilities are at an end it has become a matter of the first importance. A vast organisation has been created in order to provide the necessary machines and men for the needs of the Royal Air Force, and it seems almost certain that the full military output of which we are now capable will 